\title{
O RECURSO RETÓRICO MITATE: DEFINIÇÃO, ANÁLISE DE POEMAS DA ANTOLOGIA KOKINWAKASHÛ E QUESTÕES TRADUTOLÓGICAS
}

\author{
Olivia Yumi Nakaema
}

Resumo: Espécie de metáfora, o mitate é um recurso retórico muito comum na antologia Kokinwakashû. O objetivo deste trabalho é definir esse recurso e abordar seu uso na citada antologia. Para isso, serão abordadas questões relativas à expressão e ao conteúdo do mitate e, por fim, questões acerca do método de tradução desse recurso para outras línguas.

Palavras-chave: Literatura Clássica Japonesa; Poesia Clássica Japonesa; Waka; Retórica; Tradução.

Abstract: Kind of metaphor, the mitate is a very common rhetorical device in the anthology Kokinwakash $\hat{u}$. The objective of this work is to define this device and analyze its use in the mentioned anthology. With this aim, we will analyze questions about the expression and the content of mitate. And also questions about methods of translation of this device to other languages.

Keywords: Classical Japanese Literature; Classical Japanese Poetry; Waka; Rhetoric; Translation.

\section{Introdução}

Sendo uma espécie de metáfora, o mitate foi utilizado em larga escala em Kokinwakashû (Coletânea de Poemas de Outrora e de Hoje), do ano 905. Esta coletânea também é rica em recursos retóricos, como o kakekotoba, engo, jokotoba, makurakotoba, entre muitos outros ${ }^{2}$.

1. Mestre pelo programa de Língua, Literatura e Cultura Japonesa da Faculdade de Filosofia, Letras e Ciências Humanas, da Universidade de São Paulo, sob a orientação da Profa. Dra. Eliza Atsuko Tashiro Perez. Atualmente é mestranda pelo programa de Literatura Japonesa da Faculdade de Letras, da Universidade de Osaka, sob orientação do Prof. Dr. Katô Yôsuke. Endereço eletrônico para contato: olivia.yumi@gmail.com.

2. A antologia Kokinwakash û e os mencionados recursos retóricos foram abordados na dissertação de mestrado "Os Recursos Retóricos na Obra Kokinwakash û (Coletânea de Poemas de Outrora e de Hoje) - Uma análise 
Neste trabalho, pretendemos definir o recurso retórico mitate, com base na literatura especializada neste tema, e analisar algumas ocorrências na antologia Kokinwakashû, a partir do método de análise linguístico. Também trataremos de questões de tradução decorrentes da observação de várias traduções em diferentes línguas.

\section{Definição de mitate}

Há muitas maneiras de definir o mitate. Assim como a metáfora foi condenada por Platão ${ }^{3}$, o mitate já foi considerado também como "falsidade" (nise mono) em algumas épocas ${ }^{4}$. Das diferentes visões sobre esse recurso retórico, vamos analisar como este era visto na época de Kokinwakashû.

Definido como recurso em que se toma um objeto no lugar de outro, o mitate foi conceituado da seguinte forma por Suzuki Hideo (1990, p. 514-5):

É um método que consiste em tomar uma coisa A como sendo outra coisa $\mathrm{B}$, de modo que a coisa $\mathrm{A}$, existente na realidade, seja vista como algo que não está visível. (...) Ao ver a coisa $A$ como a coisa $B$, como a flor que é vista como a neve (...), surge entre A e B uma nova relação que não deveria existir na realidade. (...) A ação humana de ver faz com que um objeto não presente na realidade seja visto sobreposto a um objeto que está presente, como se fosse uma ilusão causada pela imaginação. Assim, essa imagem virtual inexistente na realidade passa a ser naturalmente vista como presente no simulacro dessa realidade. O mitate pode ser considerado como uma forma de simulacro nos poemas. (tradução nossa)

Assim, o mitate pode ser considerado como um método que cria um simulacro da realidade, onde um objeto A é visto como o objeto B. Esse fenômeno é possível em função da percepção visual, que gera uma substituição da imagem real de A pela imagem virtual de B. No exemplo mencionado por Suzuki (1990), a flor existente na realidade é vista como a neve, existente no simulacro apenas.

Para melhor compreender esse recurso retórico, passemos à análise do poema 60 de Kokinwakashû, da autoria de Ki no Tomonori: ${ }^{5}$

da morfossintaxe e do campo semântico do recurso Kakekotoba" de nossa autoria, pela Universidade de São Paulo, São Paulo, 2012. Disponível em: http://teses.usp.br.

3. Platão condena a metáfora por considerá-la uma mentira que afronta a verdade (RICOEUR, Paul. La métaphore vive. Paris, Éditions du Seuil, 1975, p. 15).

4. Essa é a forma como é vista o mitate em "Toshiyori Zuinô", um tratado poético elaborado por Minamoto no Toshiyori (1055?-1129?) ao final do Período Heian (HASHIMOTO, Fumio.; ARIYOSHI, Tamotsu.; FUJIHIRA, Haruo. (comentários). Karonshû (Reunião de Tratados Poéticos). Shinpen Nihon Koten Bungaku Zenshâ 87. Tóquio: Shogakukan, 2002, p. 78).

5. Todos os poemas aqui citados seguem a forma escrita da edição Kokinwakash $\hat{u}$ anotada por Kojima Noriyuki e Arai Eizô, Coleção Shin Nihon Koten Bungaku Taikei Volume 5, 6ª . edição, Editora Iwanami shoten, ano 2011. A numeração dos poemas segue a de Shinpen Kokka Taikan. 
寛平御時后宫歌合の歌

み吉野の山べにさけるさくら花雪かとのみぞあやまたれける

kanpyô no ôntoki no kisai no miya no utaawase no uta

mi yoshino no yamabe ni sakeru sakura hana

yuki ka to nomi zo ayamatarekeru

Poema composto na ocasião da Competição Poética Kanpyôno Ôntoki kisai no Miya ${ }^{6}$.

No entorno do Monte Yoshino, flores de cerejeira são vistas!

Erroneamente pensei: será neve?

(Kokinsh $\hat{u}$, tomo 1 - poemas de primavera $)^{7}$

Neste exemplo, as flores de cerejeira são confundidas visualmente com a neve. No mundo real, apenas existem flores, mas no simulacro da realidade, percebido pelo sentido da visão, existe neve.

$\mathrm{Na}$ antologia Kokinwakash , o recurso mitate era considerado elegante, por isso, foi muito utilizado em poemas, principalmente nos dos compiladores Ki no Tsurayuki, Ki no Tomonori, Ôshikôchi no Mitsune e Mibu no Tadamine.

A seguir, no item 2, abordaremos as expressões por meio das quais o mitate é estruturado e o significado que abarca.

\section{Presença do mitate em Kokinwakashû: expressão e conteúdo}

$\mathrm{Na}$ época de Kokinwakash $\hat{u}$, o mitate era visto de forma positiva, recebendo grande aceitação. Sobre isso, Ozawa Masao (1961, p. 125) esclarece:

Mitate, engo, kakekotoba, diferentemente do jokotoba e da personificação, são recursos retóricos que se desenvolveram rapidamente em poemas de Kokinwakash $\hat{u}$. Esses recursos foram utilizados até mesmo em poemas do Período dos Poetas Anônimos, mas ainda de forma primitiva. A partir dos poemas dos poetas do Rokkasen é que o registro desse desenvolvimento se torna mais evidente. (tradução nossa)

6. Competição poética de waka ocorrida por volta de 889 a 893, promovida por Hanshi, consorte do imperador Kôkô (830-887).

7. Todas as traduções dos poemas para a língua portuguesa apresentadas neste trabalho foram elaboradas pela autora com alterações sugeridas pelo parecer desta revista. 
Para o autor, há diferença no uso do mitate nos três períodos de Kokinwakash $\hat{u}^{8}$. Apesar de ser utilizado em todos os momentos, foi a partir do Período dos Poetas do Rokkasen que o mitate ganhou impulso.

Conforme nossa análise dos poemas de Kokinwakashû, observamos que em cerca de dez por cento dos poemas waka há uso de mitate. Desse modo, no item 2.1, apresentaremos as principais formas de expressão e, no item 2.2, os principais conteúdos desse recurso.

\subsection{Expressões que constroem o mitate}

Segundo apresentado por Katagiri Yôichi (1986, p. 99-101), o mitate pode ser construído com o uso de diversas expressões que são, muitas vezes, originárias do poema chinês kanshi. Com base nessas expressões levantadas por esse autor, sintetizamos a seguir as principais encontradas na antologia Kokinwakash $\hat{u}$ :
a) $\ulcorner\ldots \ldots$ と見る」(...to miru $)$
b) $「 \ldots \ldots$ かとあやまつ」(...ka to ayamatsu)
c) 「….と女ざむく」(...to azamuku)
d) $\ulcorner\ldots . .$. となる $\lrcorner($...to naru $)$
e) $\ulcorner\ldots . .$. とのみ」(...to nomi)
f) 「…..なりけク」(...narikeri)
g)「…..でありける」(...zo arikeru)

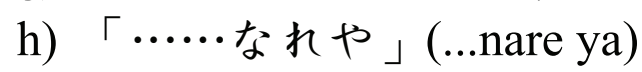

Essas expressões podem ser encontradas sob a forma de outras variantes. Deve-se ressaltar aqui que essas expressões não indicam obrigatoriamente $o$ recurso mitate, isto é, nem sempre constroem esse recurso retórico quando são utilizados. No entanto, normalmente o mitate pode ser encontrado com o auxílio de uma dessas formas de expressão. Vejamos alguns exemplos dessas expressões:

8. De acordo com a literatura especializada sobre Kokinwakashî, nesta obra foram reunidos poemas de três períodos de poetas. O primeiro é o chamado de Período dos Poetas Anônimos, que reúne poemas com estética semelhante a poemas da Antologia Man 'yôshû. O segundo é o Período dos Poetas Rokkasen, composto por seis poetas principais (Ono no Komachi, Ariwara no Narihira, Bun'ya no Yasuhide, Sôjô Henjô, Kisen Hôshi e Ôtomo no Kuronushi) e outros da mesma época. O terceiro período é chamado de Período dos Compiladores, composto pelos poetas responsáveis pela organização da antologia Kokinwakashû (Ki no Tsurayuki, Ki no Tomonori, Ôshikôchi no Mitsune e Mibu no Tadamine) e demais poetas da mesma época. Esses três períodos também foram abordamos mais amplamente na dissertação de mestrado citada na nota 2. 
a) $\ulcorner\ldots \ldots$ と見る」(...to miru)

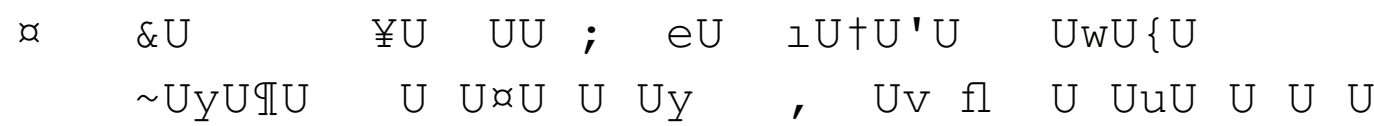

motoyasu no miko no nanasoji no ga no ushiro no byôbû ni, yomite kakikeru

haru kureba yado ni mazu saku mume no hana

kimi ga chitose no kazashi to zo miru

Poema composto sobre o biombo de fundo, na ocasião da comemoração dos setenta anos do príncipe Motoyasu.

Como é chegada a primavera, a flor da ameixeira, a primeira a florescer na casa, parece um arranjo de flores para desejar-lhe uma vida próspera.

(Kokinsh $\hat{u}$, tomo 7- poemas de felicitação, Ki no Tsurayuki, poema 352)

Neste poema, as flores de ameixeira são vistas como um kazashi, isto é, um enfeite usado na cabeça em eventos comemorativos.

b) ( UuU UlUfiUau(...ka to ayamatsu)

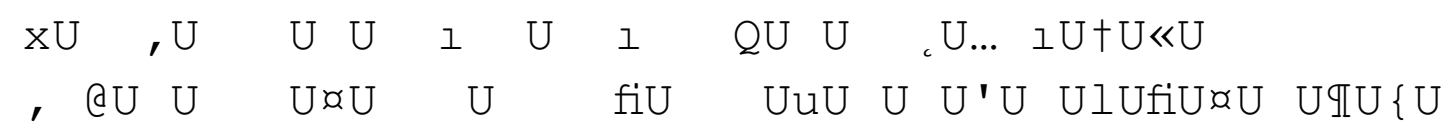

kiku no hana no moto nite, hito no, hito materu kata wo, yomeru

hana mitsutsu hito matsu toki wa shiratae no

sode ka to nomi zo ayamatarekeru

Poema composto próximo às flores de crisântemo, observando alguém que espera outra pessoa.

Ao contemplar as flores, enquanto espero aquela pessoa, parece que vejo suas brancas mangas do quimono.

(Kokinshû, tomo 5 - poemas de outono II, Ki no Tomonori, poema 274) 
Neste exemplo, a imagem real das flores brancas faz com que o poeta perceba as mangas de quimono da pessoa amada, a quem espera. Assim, ocorre o mitate entre os crisântemos e as mangas da vestimenta.

c)..「….とをむ゙むく」(...to azamuku)

蓮の露を見て、よめる

はち寸葉のにごクに染ま奻てなにかはつゆを珠とあざむく

hachisu no tsuyu wo mite, yomeru

hachisuba no nigori ni shimanu kokoro mote

nanika wa tsuyu wo tama to azamuku

Poema composto ao contemplar a gota de orvalho sobre a folha de lótus.

A folha de lótus possui um coração que não se torna impuro em meio ao lodo.

Por que se confunde a gota de orvalho com uma pedra preciosa?

(Kokinshû, tomo 5 - poema de outono II, Henjô, poema 165)

Neste poema, a gota de orvalho e a pedra preciosa se substituem por serem redondas e belas. Ou seja, na realidade, sobre a folha de lótus está a gota de orvalho, no entanto, no simulacro, é possível ver uma pedra preciosa.

d) $\ulcorner\ldots . .$. となる」(...to naru)

二条后の、春宮の御息所と聞えける時、正月三日御前に召して、 仰世言ある間に、日は照りながら、雪の頭に降り掛りけるを、よ ませ給ける

春の日の光にあたる我なれど頭の雪となるぞわびしき

nijô no kisaki no, tôgû no miyasundokoro to kikoekeru toki, mutsuki mikka omae ni meshite, ôsegoto aru aida ni, hi wa teri nagara, yuki no kashira ni furikakarikeru wo yomase tamaikeru

haru no hi no hikari ni ataru ware naredo kashira no yuki to naru zo wabishiki 
Poema composto obedecendo à ordem de elaborá-lo ao observar a neve que cobre a minha cabeça, enquanto o sol brilha radiante, no terceiro dia do primeiro mês, nos tempos em que a imperatriz de Nijô era conhecida como mãe do herdeiro imperial.

Embora banhado pela luz do sol da primavera, que tristeza! Sobre a cabeça, parece haver neve!

(Kokinshîu, tomo 1 - poemas de primavera I, Bun'ya no Yasuhide, poema 8)

Neste poema, os cabelos brancos do poeta são vistos como a neve branca, no simulacro. Ao ver a neve sobre sua cabeça, o poeta sente-se triste porque envelheceu.

e) $\ulcorner\ldots . .$. とのみ」(...to nomi)

桜の散るを、よめる

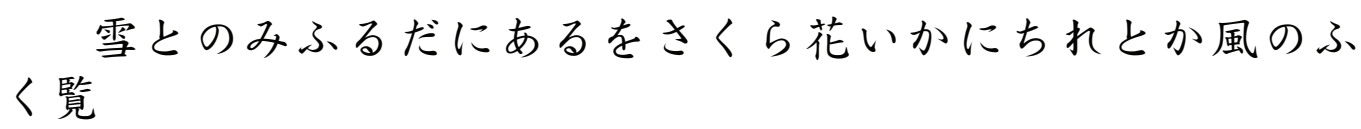

sakura no chiru wo, yomeru

yuki to nomi furu dani aru wo sakurabana

ikani chire to ka kaze no fukuran

Poema composto ao contemplar o cair das pétalas das cerejeiras.

Se as flores de cerejeira já caem como a neve, de que maneira o vento, que agora sopra, espera que elas se despetalem?

(Kokinsh $\hat{u}$, tomo 2 - poemas de primavera II, Ôshikôshi no Mitsune, poema 86)

Neste exemplo, a expressão "to nomi" é utilizada indicando uma comparação. As flores de cerejeira são comparadas à neve, uma vez que suas pétalas caem da mesma forma.

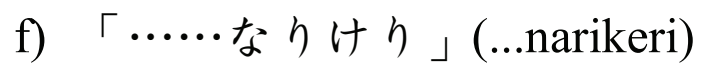


花盛りに、京を見遣りて、よめる

見わたせば柳さくらをこきまぜて宮こぞ春の錦なりける

hana sakari ni, kyô wo miyarite, yomeru

miwataseba yanagi sakura wo kokimazete

miyako zo haru no nishiki narikeru

Poema composto vendo a floração da capital.

Ao olhar ao longe, os salgueiros e as cerejeiras entrelaçados...

A capital se transforma num brocado de primavera!

(Kokinsh $\hat{u}$, tomo 1 - poema de primavera I, Sôsei Hôshi, poema 56)

Neste poema, o mitate é estruturado como uma metáfora, sem o uso de uma expressão comparativa. Apenas com o uso da expressão "narikeru", composta por um morfema gramatical flexionável de asserção "nari” acrescido do morfema gramatical flexionável de exclamação "keri”, pode-se notar que os salgueiros e as cerejeiras vistos ao longe fazem com que a capital se transforme em um brocado de primavera.

g) ( $\quad \mathrm{U} \quad \mathrm{UlU} \cdot \mathrm{U}\{\mathrm{U}(\ldots \not \supset \mathrm{o}$ arikeru $)$

$>\mathrm{A} S \cdot-\mathrm{U} \quad \mathrm{U}:$

eU $7 \cdot \mathrm{U} . . . \mathrm{U} ¥ \mathrm{U}$ UlU|U UyU $\quad \mathrm{CU} \quad œ U \quad-\mathrm{U}, \mathrm{U} \quad \mathrm{U} \quad \mathrm{UuU} \cdot \mathrm{U} \quad \mathrm{U} \quad \mathrm{UlU} \cdot \mathrm{U}\{\mathrm{U}$

kanpyô no ôntoki no kisai no miya no utaawase no uta

aki kaze ni koe wo ho ni agete kuru fune wa

ama no to wataru kari ni zo arikeru

Poema composto na ocasião da Competição Poética Kanpyô no Ôntoki kisai no Miya.

Ao vento do outono, o barco vem elevando o mastro e, elevando a voz, atravessa as portas do céu, um bando de gansos selvagens.

(Kokinsh $\hat{u}$, tomo 4 - poemas de outono I, Fujiwara no Sugane no Ason, poema 212) 
Neste poema há a ocorrência de dois exemplos de mitate. O primeiro é a substituição do céu pelo mar e o segundo, do barco pelo bando de gansos selvagens. Ou seja, o barco atravessando o mar é visto, no simulacro, como um bando de gansos selvagens que atravessa o céu.

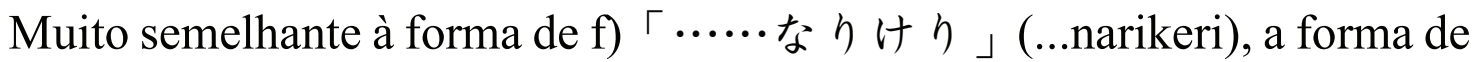
g) é composta de um verbo mais o morfema gramatical flexionável de exclamação "keri" sem o uso de uma expressão comparativa, produzindo efeito de sentido igual ao de uma metáfora.

h) $\ulcorner\ldots . .$. なれや」(...nare ya)

是貞親王家歌合に、よ妇

秋の野にをくしらつゆは珠なれやつらぬきかくる蜘蛛の いとすぢ

Koresada no miko no ie no utaawase ni, yomeru

aki no no ni oku shira tsuyu wa tama nare ya

tsuranuki kakuru kumo no itosuji

Poema composto na Competição Poética da residência do Príncipe Koresada.

No campo de outono, as brancas gotas de orvalho que se põem sobre o ninho da aranha são um colar de pedras preciosas!

(Kokinshî, tomo 4-poemas de outono 4, Bun'ya no Asayasu, poema 225)

No exemplo, a realidade formada por brancas gotas de orvalho que se depositam sobre a teia de aranha é vista, no simulacro, como um colar de pedras preciosas. A expressão que constrói o mitate é "nare ya", formada pelo morfema gramatical flexionável de asserção "nari" acrescido pelo morfema gramatical inflexionável que expressa exclamação "ya".

\subsection{Conteúdos mais comuns no mitate}

Pelos exemplos apresentados no item 2.1, pudemos notar que há formação de mitate com elementos dos campos semânticos naturais e humanos.

Em nossa análise dos poemas de Kokinwakashu, verificamos que a imagem mais comum de mitate é a que combina neve e flor. São comuns poemas em que a 
neve é vista como flor e poemas em que, ao contrário, a flor é vista como a neve. $\mathrm{O}$ ponto comum entre esses objetos são a cor e a forma com que caem. Nesse caso, há dois elementos naturais sendo substituídos.

Outro tipo de mitate muito comum é o que combina gotas de orvalho e pedras preciosas. Ambas são brancas, redondas e consideradas belas, por isso, são substituídas reciprocamente. Também é comum substituir a gota de orvalho pela lágrima, por possuírem essas mesmas características. Assim, podemos notar que os elementos reunidos no mitate possuem pontos de contato que os permitem ser igualados.

Os objetos humanos que mais formam mitate são partes da vestimenta (manga e barra do quimono, kazashi); navio, espelho, brocado, entre outros. E os objetos naturais mais presentes no mitate são: neve, flores, onda, gotas de orvalho, ácer, entre outros.

\section{Questões tradutológicas acerca do mitate}

Kokinwakashû é uma das antologias de poemas clássicos japoneses mais traduzidas em todo o mundo. Apesar de não haver ainda uma tradução para a língua portuguesa, compararemos a tradução de dois poemas com mitate em diferentes línguas (inglesa, espanhola, italiana e francesa), com o objetivo de analisar o método pelo qual este recurso estilístico tem sido traduzido. Devemos ressalvar aqui que a análise de traduções não corresponde a uma busca de "erros de tradução", mas é uma reflexão sobre diferentes métodos.

Como definimos anteriormente no item 1, mitate é um recurso retórico que consiste em tomar um objeto como se fosse outro. Por ser um tipo de metáfora, pela definição clássica de Aristóteles, pode ser na forma de metáfora ou comparação, dependendo do uso ou não de uma expressão explicativa, como "como", "assim como", "parecendo", entre outras.

Vejamos o caso do poema 331, do poeta Ki no Tsurayuki, da antologia Kokinwakashô:

$$
\begin{gathered}
\text { 雪の、木に降り懸孔りけるを、よめる } \\
\text { 冬ごもり思かけぬを木の間より } \\
\text { 花と見るまで雪ぞふりける }
\end{gathered}
$$

yuki no, ki ni furikakarerikeru wo, yomeru

fuyugomori omoikakenu wo ko no ma yori

hana to miru made yuki zo furikeru 
Poema composto ao ver a neve que cai encobrindo as árvores.

Em pleno inverno, sem que ninguém perceba, entre as árvores, como se fossem flores, cai a neve!

(Kokinsh $\hat{u}$, tomo 6- poemas de inverno)

Neste exemplo, em um contexto de inverno, época em que não há flores, entre as árvores cai a neve como se fossem flores. Por meio do mitate, constrói-se um simulacro resultante da percepção do sujeito onde há flores caindo. Para estruturar o mitate, foi utilizada a expressão "to miru made". Passemos agora às diversas traduções deste poema, a fim de observar como o mitate foi traduzido.

$\mathrm{Na}$ tradução de Renondeau (2004) para a língua francesa, a seguir, a expressão "to miru made" foi traduzida como "On croirait voir des fleurs" (cremos ver flores).

Au coeur de l'hiver,

Contrairement à toute atente,

Au milieu des arbres

On croirait voir des fleurs

Tant il est tombé de neige. ${ }^{9}$

Da mesma forma que no poema japonês, nesta tradução existe a construção de um simulacro em que flores são vistas, uma vez que o uso do verbo "crer", cria um efeito de sentido semelhante ao original. $\mathrm{O}$ mesmo ocorre na tradução para a língua italiana de Sagiyama (2000), a seguir:

Sulla neve che ammantava gli alberi.

In pieno inverno

mai si aspetta la fioritura:

ma tra gli alberi,

9. Nossa tradução do poema francês:

No coração do inverno,

Contrariamente a qualquer espera,

No meio das árvores

Cremos ver flores

De tanto que cai a neve. 
quasi petali volteggianti, ecco, fiocca la neve. ${ }^{10}$

Na tradução italiana, a expressão "hana to miru made" foi traduzida por "quasi petali volteggianti" (como pétalas voltejando). A expressão comparativa "quase" equivale às expressões "como", "parecendo" e "como se fosse" da língua portuguesa. No simulacro existe neve que precipita como pétalas (metonímia de flor) que caem dançando no ar.

No poema traduzido para a língua espanhola por Rubio (2005), o mitate foi traduzido sem uso de uma expressão comparativa, mas por meio do uso de interrogação, gerando assim um efeito de suposição acerca do simulacro percebido.

Sobre el manto nevado sobre los árboles
En pleno invierno, en medio de los árboles, sin esperarlo, ¿son ésas, que entre tanta nieve se asoman, flores? ${ }^{11}$

Enquanto no poema original a comparação entre as flores e a neve está claramente indicada em "entre as árvores, como se fossem flores, cai a neve!", nesta tradução espanhola, nota-se que há uma suposição acerca da metáfora entre as flores e a neve, isto é, há um questionamento sobre as flores estarem presentes

10. Nossa tradução do poema italiano:

Sobre a neve que cobria as árvores.

Em pleno inverno

sem que se esperasse o florescer:

entre as árvores,

como pétalas voltejando,

eis que a neve cai.

11. Nossa tradução do poema em língua espanhola:

Sobre o manto de neve sobre as árvores

Em pleno inverno,

em meio das árvores,

sem serem esperadas,

são essas que entre tanta

neve despontam flores? 
ou não junto da neve. Portanto, o simulacro criado na tradução espanhola não é o mesmo que no poema original.

Na tradução inglesa de Rodd \& Henkenius (1984), o mitate passou a ser expresso por "I/ glimpse new flowers" (vejo de repente flores novas):

On snow blanketing the trees.

in winter when all's

sleeping unexpectedly

between the trees I

glimpse new flowers glistening

crystal white snow has fallen ${ }^{12}$

Nessa tradução vê-se a substituição da imagem da neve pela imagem das flores, criando o mesmo simulacro que no poema original.

Como se pode observar, com exceção da tradução espanhola de Rubio (2005), o mitate foi traduzido preservando o simulacro presente no poema original. Além disso, em algumas vezes, houve uma aproximação com a comparação, como na tradução italiana de Sagiyama (2000), e com a metáfora, como na tradução inglesa de Rodd \& Henkenius (1984). No caso de tradução na forma de comparação, a expressão japonesa "to miru made" foi corretamente traduzida com o uso de expressões comparativas.

Vejamos agora traduções de um poema com mitate do tipo metafórico, sem a presença de uma expressão comparativa. Tomemos o exemplo do poema 9 , também do poeta Ki no Tsurayuki, compilado em Kokinwakash $\hat{\text { : }}$

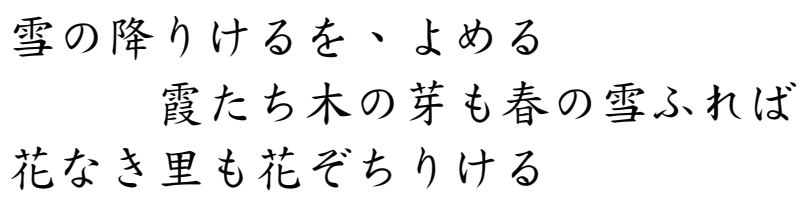

yuki no furikeru wo, yomeru

12. Nossa tradução do poema em inglês:

Na neve cobrindo as árvores.

no inverno quando tudo está

dormindo inexplicavelmente

entre as árvores eu

vejo de repente flores novas brilhantes

branca cristalina, a neve cai 
kasumi tachi ko no me mo haru no yuki fureba

hana naki sato mo hana zo chirikeru

Poema composto ao contemplar o cair da neve.

Paira a névoa e os brotos nas árvores despontam. Com o cair da neve de [primavera

em um vilarejo em que não há flores, flores se despetalam.

(Kokinsh $\hat{u}$, tomo 1 - poema de primavera I)

Nesse poema, a explicação introdutória (kotobagaki) já deixa claro o contexto de criação do poema, isto é, uma situação em que a neve cai em um lugar onde não há flores. No entanto, a neve que cai é vista como pétalas de flores, pois caem de forma semelhante. Assim, o mitate atua como uma metáfora, sem uso de qualquer expressão comparativa, construindo um simulacro da realidade. Nesse caso, o efeito de sentido produzido é diferente do produzido na comparação, pois aproxima mais diretamente os objetos metaforizados sob a forma de asserção. Vejamos como este poema foi traduzido em três outras línguas.

Na tradução de Rodd \& Henkenius (1984), também não há uso de expressão comparativa:

On falling snow.

when the warm mists veil

all and buds swell while yet the

spring snows drift downward

even in the hibernal

village crystal blossoms fall ${ }^{13}$

13. Nossa tradução do poema em inglês:

Ao cair da neve.

quando a névoa tépida encobre

tudo e os brotos crescem... enquanto ainda a

neve de primavera cai

mesmo em um invernal

vilarejo... cerejeiras cristalinas caem. 
Neste poema em inglês, pode-se observar que o mitate foi traduzido como uma metáfora, ao considerar que a neve é a flor. O mesmo método de tradução foi utilizado na versão de língua espanhola e italiana, que se seguem:

Na tradução de Duthie (2005), também não há uso de expressão comparativa, mas sim tradução sob a forma de metáfora. Vejamos:

Compuesto con motivo de la nieve que había caído.

Se levanta la neblina

$\mathrm{y}$ entre los brotes de primavera

al caer la nieve,

hasta en los pueblos sin flores

las flores se derraman. ${ }^{14}$

Na tradução em italiano de Sagiyama (2000), a seguir, há uso da metáfora entre os flocos de neve e as pétalas de flores:

Sulla neve che cade.

È primavera: la foschia si leva

e gli alberi germogliano,

cade ancora a fiocchi la neve

ed ecco, nel paese pur disadorno

di fiori, i petali volteggiano lievi. ${ }^{15}$

14. Nossa tradução do poema em espanhol:

Composto tendo como tema a neve que havia caído.

Se levanta a neblina

e entre os brotos de primavera

ao cair da neve,

até em vilarejos sem flores

as flores se derramam.

15. Nossa tradução do poema italiano:

Sobre a neve que cai.

É primavera: a névoa se levanta

e as árvores que germinam,

cai agora a neve em flocos

e de repente, no país em que não tem adornos

de flores, cai a leve pétala volteando. 
Como se pode observar, nos poemas em que o mitate é estruturado sem o uso de expressão comparativa, é comum a sua tradução como metáfora e não como comparação. Em que pese o fato de a comparação ser mais explicativa sobre o conteúdo do poema, é desvantajoso traduzir todo mitate como comparação, uma vez que os efeitos de sentido na comparação e na metáfora são diferentes. Desse modo, se o poema original contiver um mitate na forma de comparação, acreditamos que a tradução também na forma de comparação é a melhor opção. Da mesma forma, se o poema original contiver um mitate na forma de metáfora, consideramos que a tradução na forma de metáfora é a melhor opção.

\section{Conclusão}

O objetivo deste trabalho foi definir o recurso retórico mitate, analisar como ocorre na antologia Kokinwakashû e sintetizar as formas de expressão e conteúdo por meios das quais se manifesta.

No item 1, definimos o mitate como um método que toma um objeto existente na realidade por outro, criando um simulacro em que um objeto substitui outro.

No item 2, reunimos as expressões que contribuem para a construção do mitate, citando exemplos concretos de como se manifesta.

No item 3, apresentamos algumas traduções de dois poemas de Kokinwakashî, analisando as formas com que foram traduzidos para outra língua. Se o mitate for uma metáfora na língua de partida, em que não há uso de expressão comparativa, opinamos pela sua tradução igualmente como metáfora. Da mesma maneira, no caso de o mitate ser uma comparação na língua de partida, opinamos pela necessidade de se manter na tradução a forma de comparação, fazendo uso de expressão comparativa. Desse modo, é possível preservar o efeito poético do texto original.

\section{Bibliografia}

DUTHIE, T. Poesía Clásica Japonesa [Kokinwakashû]. Traducción del japonés y edición de Torquil Duthie. Madrid: Trotta, 2008.

HASHIMOTO, Fumio.; ARIYOSHI, Tamotsu.; FUJIHIRA, Haruo. (comentários). Karonshû (Reunião de Tratados Poéticos). Shinpen Nihon Koten Bungaku Zenshû 87. Tóquio: Shogakukan, 2002.

KATAGIRI, Yôichi. Mitate to sono jidai - Kokinshû Hyôgenshi no Isshô toshite (O Mitate e sua época: um RENONDEAU, Gaston. Anthologie de la poésie japonaise classique. Traduction, Préface et commentaires de G. Renondeau. Paris: Gallimard, 2004.capítulo sobre a história das expressões de Kokinshû). Waka to Retorikku (Waka e Retórica). Tóquio: Kasamashoin, 1986.

OZAWA, Masao. Kokinshû no Sekai (O mundo de Kokinshû). Tóquio: Hanawashobô, 1961. 
RENONDEAU, Gaston. Anthologie de la poésie japonaise classique. Traduction, Préface et commentaires de G. Renondeau. Paris: Gallimard, 2004.

RICOEUR, Paul. La métaphore vive. Paris, Éditions du Seuil, 1975.

RODD, L. R.; HENKENIUS, M. C. Kokinshû. A Collection of Poems Ancient and Modern. Translated and annotated by Laurel Rasplica Rodd with Mary Catherine Henkenius. New Jersey: Princeton University Press, 1984.

RUBIO, C. Kokinshuu. Colección de poemas japoneses antiguos y modernos (El canon del clasicismo). Selección, traducción, introducción y notas de Carlos Rubio. Edición Bilingüe. Madrid: Hiperion, 2005.

SAGIYAMA, I. Kokin Waka Shû. Raccolta di poesie giapponesi antiche e moderne. A cura di Ikuko Sagiyama (testo giapponese e trascrizione). 1 ed. $2^{\text {a }}$. reimpressão. Milano: Ariele, 2008.

SUZUKI, Hideo. Kodai Wakashiron (Tratado sobre a História do Waka no Período Clássico). Tóquio: Tôkyô Daigaku Shuppankai, 1990.

SUZUKI, Hiroko. Kokinwakashû Hyogenron (Tratado sobre as expressões em Kokinwakashû). Tóquio: Kasamashoin: 2000. 